\title{
A scientific note on hive entrance smearing in Japanese Apis cerana induced by pre-mass attack scouting by the Asian giant hornet Vespa mandarinia
}

\author{
Ayumi FuJIWARA $^{1}$, Masami SASAKI ${ }^{2}$, Izumi WaShITANI ${ }^{3}$ \\ ${ }^{1}$ Graduate School of Agricultural and Life Sciences, The University of Tokyo, 1-1-1 Yayoi, Bunkyo-ku, Tokyo 113-8657, Japan \\ ${ }^{2}$ Honeybee Science Research Center, Tamagawa University, 6-1-1 Tamagawagakuen, Machida, Tokyo 194-8610, Japan \\ ${ }^{3}$ Laboratory of Conservation Ecology, Department of Integrated Science and Engineering for Sustainable Society, Faculty of \\ Science and Engineering, Chuo University, 1-13-27 Kasuga, Bunkyo-ku, Tokyo 112-8551, Japan
}

Received 6 October 2015 - Revised 25 December 2015 - Accepted 2 February 2016

\section{Apis cerana / Vespa mandarinia / plant materials / propolis / defensive strategy}

Vespa mandarinia is one of the most important natural enemies of Japanese Apis cerana (Ono et al. 1995). $V$. mandarinia attacks the nests of $A$. cerana to feed its brood in autumn, as do other species of wasps such as Vespa simillima xanthoptera. A well-known colonylevel defence of $A$. cerana against Vespa attack is the formation of a hot defensive ball, a huge aggregation of worker bees whose collective body heat (Ono et al. 1987, 1995), combined with increased carbon dioxide from respiration, kills the wasps (Sugahara et al. 2012).

Another A cerana behaviour thought to be a defensive strategy to prevent predation by $V$. mandarinia is 'entrance smearing' with unknown materials, as suggested by Okada (1997) and Sasaki (1999). The use of plant materials other than pollen or nectar by $A$. cerana for non-nutritional purposes has not yet been demonstrated; A. cerana has been reported to gnaw leaves at the centre of green head lettuce (Yokoi 2005, 2015) in autumn. Here, we report the plant-gnawing behaviour of $A$. cerana attributable to the collection of plant materials used to smear around the hive entrance, leaving dark-coloured stains similar to those described by Okada (1997) and Sasaki (1999).

We hypothesized that the smearing of collected plant materials is part of a colony-defence strategy that evolved specifically to counter the foraging attacks of

Corresponding author: A. Fujiwara,

fujiwara328@gmail.com

Manuscript editor: James Nieh
V. mandarinia. To test this hypothesis, we (1) tracked plant-gnawing bees to reveal whether they brought plant materials they collected back to the hive; (2) evaluated the seasonality of entrance smearing in total 20 hives to show that the behaviour occurs only in autumn, when Vespa attack is common; and (3) performed a series of attack simulation experiments using $V$. mandarinia, $V$. simillima xanthoptera, and Vespa analis to confirm that the induction of entrance smearing was a specific response to $V$. mandarinia scouting.

We evaluated $A$. cerana colonies introduced into observational hives in a rural landscape near Ichinoseki City in Iwate Prefecture (apiary A: $38^{\circ} 92^{\prime} 77.14^{\prime \prime} \mathrm{N}$, $141^{\circ} 03^{\prime} 31.76^{\prime \prime} \mathrm{E}$; apiary B: $38^{\circ} 93^{\prime} 77.22^{\prime \prime} \mathrm{N}, 140^{\circ} 99^{\prime}$ $\left.00.49^{\prime \prime} \mathrm{E}\right)$, northern Japan. Over 5 years of observations and 'attack simulation' experiments, we observed in total 12 colonies in apiary $\mathrm{A}$ and in total 8 colonies in apiary $\mathrm{B}$, which are separated by $4 \mathrm{~km}$.

We tracked plant-gnawing bees in early October 2011. We individually marked ten worker bees visiting a Persicaria nepalensis (Meisn.) H. gross patch in the vicinity of four colonies (apiary A), using coloured paint, and then monitored the hive entrances and, later, the same $P$. nepalensis patch.

We found that the bees gnawed the leaves, calyxes, petals, and buds of the plants (Figure 1a) and then returned to their hives to smear the collected plant materials around the entrances (Figure 1b, c). However, we were unable to determine whether all the staining materials were of plant origin. Most of the smeared materials eventually darkened, turning black or dark brown. 

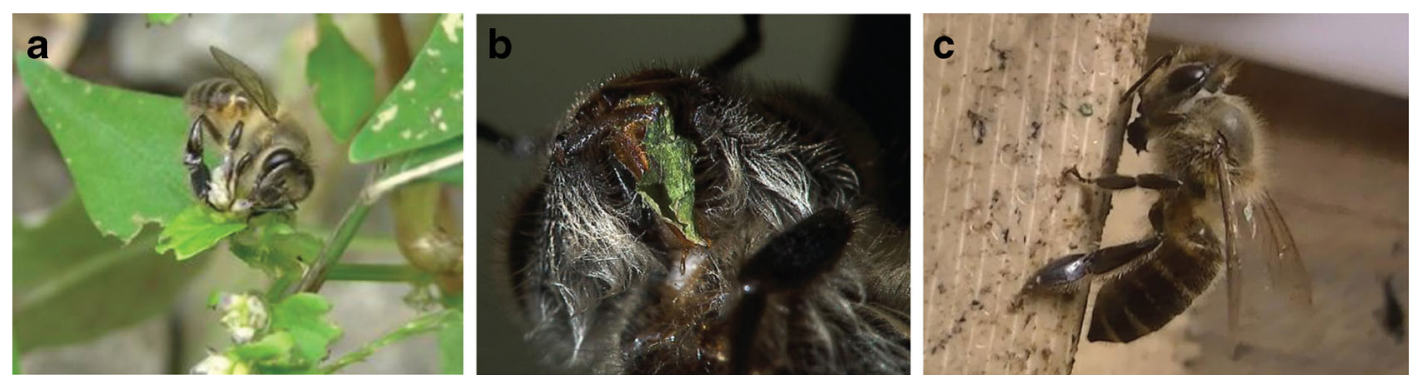

Figure 1. A worker gnawing P. nepalensis near the hive. a Multiple bite marks on the leaves. b Ventral view of a worker bee holding plant material between its mandibles and proboscis. $\mathbf{c}$ Smearing the gnawed material on the hive entrance.

To investigate the seasonality of smeared plant materials, we observed patches $(>0.5 \mathrm{~mm}$ in diameter) around the entrances of a total of 20 colonies by eye and by video recording at least once a month during the annual A. cerana active season (April-October) from 2011 to 2015. Dark-coloured stains, presumably from the discoloured, smeared plant materials, were much more frequent in September and October (autumn). Most stains were concentrated within $15 \mathrm{~cm}$ of the hive entrance, and the number of stains increased with time during autumn.

To simulate Vespa attack, we divided six honeybee colonies into three pairs and subjected each pair to experiments in 2015 with one of the three hornet species: $V$. mandarinia, the suspected inducers of entrance smearing, along with $V$. simillima xanthoptera and $V$. analis, which are sympatric with $A$. cerana and sporadically attack honeybee hives (Ono et al. 1987). We carried out attack simulation experiments using each Vespa species to simulate the scouting behaviour of the respective species. In the V. mandarinia experiments, we forced the experimental hornet fastened by its slender petiole to a fine wire (Tan et al. 2012) to fly around the bee hive for $30 \mathrm{~s}$ and then to walk around the hive entrance for $30 \mathrm{~s}$. Each treatment consisted of five cycles of hornet flight/walking, and the treatment cycles were repeated four times for each bee colony: twice on July 21 and once each on July 22 and 23. In the V. simillima xanthoptera or $V$. analis experiments, the hornets were forced to hover near the entrance of the hive, which was achieved by allowing them to flap their wings freely for $1 \mathrm{~min}$. As above, bee colonies were subjected to four replicates of five treatment cycles with these hornet

Table I. The results of a series of attack simulation experiments performed from July 21 to July 23 with three hornet species.

\begin{tabular}{|c|c|c|c|c|c|c|c|c|c|}
\hline \multirow[t]{2}{*}{ Vespa species } & \multirow[t]{2}{*}{ Apiary } & \multirow{2}{*}{$\begin{array}{l}\text { Colony } \\
\text { no. }\end{array}$} & \multicolumn{7}{|l|}{ Date } \\
\hline & & & $\begin{array}{l}18 \text { July } \\
2015 \\
\text { Before } \\
\text { experiment }\end{array}$ & $\begin{array}{l}\text { 19 July } \\
2015\end{array}$ & $\begin{array}{l}20 \text { July } \\
2015\end{array}$ & $\begin{array}{l}21 \text { July } \\
2015 \\
\text { After } \\
\text { experiment }\end{array}$ & $\begin{array}{l}22 \text { July } \\
2015\end{array}$ & $\begin{array}{l}23 \text { July } \\
2015\end{array}$ & $\begin{array}{l}28-29 \text { July } \\
2015 \\
\text { Additional } \\
\text { experiment }\end{array}$ \\
\hline \multirow[t]{2}{*}{ Vespa mandarinia } & $\begin{array}{l}\text { Apiary } \\
\text { B }\end{array}$ & $\begin{array}{c}\text { Colony } \\
1\end{array}$ & $\times$ & $\times$ & $\times$ & ० & $\circ$ & $\circ$ & $\circ$ \\
\hline & & $\begin{array}{c}\text { Colony } \\
2\end{array}$ & $\times$ & $\times$ & $\times$ & ० & $\circ$ & ० & $\circ$ \\
\hline \multirow[t]{2}{*}{$\begin{array}{l}\text { Vespa simillima } \\
\text { xanthoptera }\end{array}$} & $\begin{array}{c}\text { Apiary } \\
\text { A }\end{array}$ & $\begin{array}{c}\text { Colony } \\
3\end{array}$ & $\times$ & $\times$ & $\times$ & $\times$ & $\times$ & $\times$ & $\times$ \\
\hline & & $\begin{array}{c}\text { Colony } \\
4\end{array}$ & $\times$ & $x$ & $\times$ & $\times$ & $\times$ & $x$ & $\circ$ \\
\hline \multirow[t]{2}{*}{ Vespa analis } & $\begin{array}{c}\text { Apiary } \\
\text { A }\end{array}$ & $\begin{array}{l}\text { Colony } \\
5\end{array}$ & $\times$ & $\times$ & $\times$ & $\times$ & $\times$ & $\times$ & ० \\
\hline & & $\begin{array}{l}\text { Colony } \\
6\end{array}$ & $\times$ & $\times$ & $\times$ & $\times$ & $\times$ & $\times$ & $\circ$ \\
\hline
\end{tabular}

Additional V. mandarinia experiments were performed on July 28-29

$\circ$ detection of entrance smearing, $\times$ no detection 
species on the same dates as the $V$. mandarinia experiments. We checked the presence or absence of entrance smearing and staining $30 \mathrm{~min}$ and 3 days after each treatment via naked-eye observations and video. Fivesix days after the attack simulation experiments, i.e. on July 28-29, all experimental bee colonies were subjected to an additional attack simulation experiment using V. mandarinia, also comprising five cycles.

Before and after the attack simulation experiments with $V$. mandarinia, we randomly collected 100 workers with a butterfly net from each of the two colonies to determine if they had ingested plant materials. These experiments were conducted twice on 28-29 July. We used Fisher's exact probability test to detect significant differences in the percentages of workers that brought back collected plant materials before and after the attack simulation experiments by $V$. mandarinia .

Only $V$. mandarinia attack induced entrance smearing in the experimental bee colonies. Smearing started 15-30 min after attack simulation began, irrespective of the exposure date and time. Neither plant-collecting nor plant-smearing responses were observed when the other colonies were exposed to simulated attack from $V$. simillima xanthoptera or $V$. analis (Table I). The number of workers that brought plant materials increased after the experimental exposure to $V$. mandarinia (Fisher's exact probability test $P<0.01$ ). In colonies in which no entrance smearing was observed in the first experiment with $V$. simillima xanthoptera and $V$. analis, smearing was induced by additional exposure to $V$. mandarinia scouting (Table I).

Overall, our study revealed a close relationship between the previously reported leaf-gnawing behaviour of A. cerena (Yokoi 2005, 2015) and the occurrence of dark-coloured stains around the entrances to the hives of these bees (Okada 1997; Sasaki 1999). The purpose of this behaviour is presumably to prevent mass attack by giant hornets. How the smeared materials counteract $V$. mandarinia attack remains unknown, but they may alter the activity or recognition of the hornet 's forage site-marking pheromone (Ono et al. 1995). A. cerana did not practise entrance smearing against $V$. simillima xanthoptera and $V$. analis, presumably because these species are less powerful enemies (Tan et al. 2013) and do not use recruitment pheromones.

Similar entrance smearing has been described for A. cerana in Vietnam and Korea, where V. mandarinia and its different subspecies are sympatric (Sasaki and Fujiwara unpublished data). Therefore, among Asian honeybees, this type of entrance smearing seems to be a common counteraction against Asian hornets of the genus Vespa .

\section{ACKNOWLEDGMENTS}

We thank G. Chisaka (Kubokawa Ihatov Nature Restoration Project) for making the study area available to us. We are grateful to M. Tanaka with respect to his expert opinion about plant-gnawing behaviour and Vespa attack. We are grateful to R. Sato, M. Tamukai, S. Fujiwara and Y. Fujiwara (Japanese Original Honeybee Organization) with respect to the hornet observation and experiment. This work was supported by Grant-inAid for JSPS Fellows Grant Number 15J07621 and by JSPS KAKENHI Grant Number 26292181.

Note scientifique sur un comportement de l'abeille japonaise, Apis cerana, déclenché par la première approche d'un frelon asiatique Vespa mandarinia et consistant à appliquer autour de l'entrée de la ruche une "bouillie végétale"

Eine wisenschaftliche Notiz zum Beschmieren des Stockeingangs mit Pflanzenmaterial bei Apis cerana in Japan, ausgelöst durch Kundschafter der asiatischen Riesenhornisse Vespa mandarinia

\section{REFERENCES}

Okada, I. (1997) Natural history of Japanese honeybee. Tamagawa University Press, Japan (In Japanese)

Ono, M., Okada, I., Sasaki, M. (1987) Heat production by balling in the Japanese honeybee, Apis cerana japonica as a defensive behavior against the hornet, Vespa simillima xanthoptera (Hymenoptera: Vespidae). Experientia 43, 1031-1032

Ono, M., Igarashi, T., Ohno, E., Sasaki, M. (1995) Unusual thermal defence by a honeybee against mass attack by hornets. Nature 377, 334-336

Sasaki, M. (1999) Wonders of the Japanese honeybee-Biology of Northernmost Apis cerana. Kaiyusya, Japan (In Japanese)

Sugahara, M., Nishimura, Y., Sakamoto, F. (2012) Differences in heat sensitivity between Japanese Honeybees and hornets under high carbon dioxide and humidity conditions inside bee balls. Zoolog. Sci. 29(1), 30-36

Tan, K., Wang, Z., Li, H., Yang, S., Hu, Z., Kastberger, G., Oldroyd, B.P. (2012) An 'I see you' prey-predator signal between the Asian honeybee (Apis cerana) and the hornet (Vespa velutina ). Anim. Behav. 83, 879-882

Tan, K., Wang, Z., Chen, W., Hu, Z., Oldroyd, B.P. (2013) The 'I see you' prey-predator signal of Apis cerana is innate. Naturwissenschaften 100, 245-248

Yokoi, T. (2005) Observation of honeybee Apis cerana gnawing the lettuce. Honeybee Sci. 26, 98-100

Yokoi, T. (2015) Visitation and gnawing behaviour of Japanese honeybee Apis cerana japonica to lettuce. Apidologie 46, 489-494 